\title{
A NOTE ON THE CORRELATION BETWEEN RAINFALL AND THE PREVALENCE OF GNATHOSTOMA SPP. INFECTIVE STAGE LARVAE IN SWAMP EELS IN THAILAND
}

\author{
WIWANITKIT V.*
}

\section{Summary:}

Gnathostoma spinigerum is the major causative agent of human gnathostomiasis, a parasitic zoonosis with a great variety of clinical manifestations. Generally, humans are infected by consumption of third-stage larvae (L3) of $G$. spinigerum in infected hosts in the form of partially cooked or uncooked food. Surveys of the contamination of Gnathostoma spp. L3 in swamp eels are useful for prevention and control of diseases and have been continuously performed in Thailand. The author performed a retrospective study on 33 previous cross-sectional surveys with geographical data and the prevalence of Gnathostoma spp. L3 that covered 12 provinces in Thailand. The relation between rainfall (derived from the geographical data) and the prevalence of Gnathostoma spp. L3 in swamp eels (derived from the overall infection rate of Gnathostoma spp. L3) was investigated. The leastsquare equation plot rainfall $(y)$ versus prevalence $(x)$ is $y=$ $9.68 x+1.035 .12(r=0.83 ; p<0.01)$. A significant correlation was discerned between rainfall and the prevalence of eel infection but not for the season of the survey. Similar to the previous study, the prevalence of eel infection may depend on rainfall rather than season. However, this study focused on only 33 cross-sectional surveys in Thailand; further similar study in other countries to assess the correlation between rainfall and the prevalence of infection is required to substantiate this conclusion.

KEY WORDS : rainfall, Gnathostoma spinigerum, eel, Thailand.

\begin{abstract}
Résumé : CORRÉLATION ENTRE LA PLUVIOSITÉ ET LA PRÉVALENCE DE LARVES INFESTANTES DE GNATHOSTOMA SPP. CHEZ L'ANGUILIE D'EAU DOUCE EN THAILANDE

Gnathostoma spinigerum est le principal agent de la gnathostomose humaine, une zoonose parasitaire aux manifestations cliniques très variées. Habituellement, l'homme est contaminé par des larves de stade 3 (L3) de G. spinigerum d'hôtes infectés consommés crus ou insuffisemment cuits. La surveillance de la contamination des anguilles d'eau douce par les L3 de Gnathostoma spp. pour la prévention et le contrôle de la maladie est menée régulièrement en Thailande. L'auteur a effectué une analyse rétrospective portant sur les 33 précédentes surveillances en croisant les données gégraphiques et la prévalence des 13 de Gnathostoma spp. dans 12 provinces de Thailande. II a étudié de façon croisée la relation entre la pluviosité (y) et la prevalence de 13 de Gnathostoma spp. chez l'anguille $(x)$ d'où il ressort l'équation: $y=9,68 x+1035,12$ ir $r=0,83 ; p<0,011$. Une corrélation significative a été observée entre la prévalence de l'infection chez l'anguille et la pluviosité, mais pas la saison. Conformément aux données des études de surveillance, la prévalence de l'infection chez l'anguille dépendrait des pluies plutôt que des saisons. Cependant, afin de confirmer cette corrélation entre pluviosité et prévalence, des études similaires devraient être menées dans d'autres pays.
\end{abstract}

MOTS CLÉS : pluviosité, Gnathostoma spinigerum, anguille, Thailande.

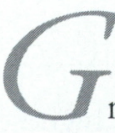
Tnathostoma spinigerum is the major causative agent of human gnathostomiasis, a parasitic zoonosis with a great variety of clinical manifestations (Daengsvang, 1980; Daengsvang, 1986; Radomyos \& Daengsvang, 1987). Generally, humans are infected by consumption of third-stage larvae (L3) of G. spinigerum in infected hosts in the form of partially cooked or uncooked food. In general, this infection is found mainly in Asia and Latin America where raw and pickled fish are part of the diet (CDC, 1999). The human infection with this parasite is fairly common in Thailand. Surveys of the contamination of Gnathostoma spp. L3 in swamp eels (Fluta alba) are useful for prevention and control of diseases and have been continuously performed in Thailand.

As the prevalence of G. spinigerum L3 infection was found to be higher in them than in other fish species, swamp eels are now considered the most important

\footnotetext{
* Department of Laboratory Medicine, Faculty of Medicine, Chulalongkorn University, Bangkok, Thailand.

E-mail: wviroj@yahoo.com
}

of this parasite's second intermediate hosts (Nuamtanong et al., 1998; Rojekittikhun et al., 1989). Rojekittikhun et al. (1989) said that there was a seasonal variation on the intensity of parasite contamination in the swamp eels, infection abruptly decreased soon after the completion of the rainy season and started to rise when the rain had come. However, Saksirisampant et al (2002a) reported that the intensity and prevalence of eel infection might also depend on rainfall, corresponding to the life cycle of $G$. spinigerum, which requires fresh-water sources for development. Here, the relation between rainfall and the prevalence of Gnatbostoma spp. L3 in swamp eels was investigated.

\section{MATERIALS AND METHODS}

ummary of the previous surveys in Thailand This study was designed as a descriptive retrospective study. The author performed the literature 
review on surveys of the contamination of Gnathostoma spp. L3 in swamp eels in Thailand from a database of the published works cited in the PubMed, MEDLINE, CAB Health Database, Science Citation Index and Thai Index Medicus. As a result of the literature review, four reports were recruited for further study.

\section{Data of rainfall distribution of Thailand}

Data of rainfall distribution of Thailand were derived from the Royal Irrigation Department, Thailand. Average yearly rainfall distribution images of Thailand are presented in Figure 1 (GIS picture, created by High Performance Computing Center/NECTEC Thailand).

Study for the relation between rainfall and the prevalence of Gnathostoma spp larvae

The geographical data and the overall infection rate of Gnathostoma spp L3 in all included reports were studied. Rainfall was derived from the geographical data and the prevalence of Gnathostoma spp. L3 in swamp eels was derived from the overall infection rate of $G n a$ thostoma spp. L3. Regression analysis was used for determining the correlation between rainfall and the prevalence of Gnathostoma spp L3 in swamp eels. The least-square equation plot rainfall $(y)$ versus prevalence

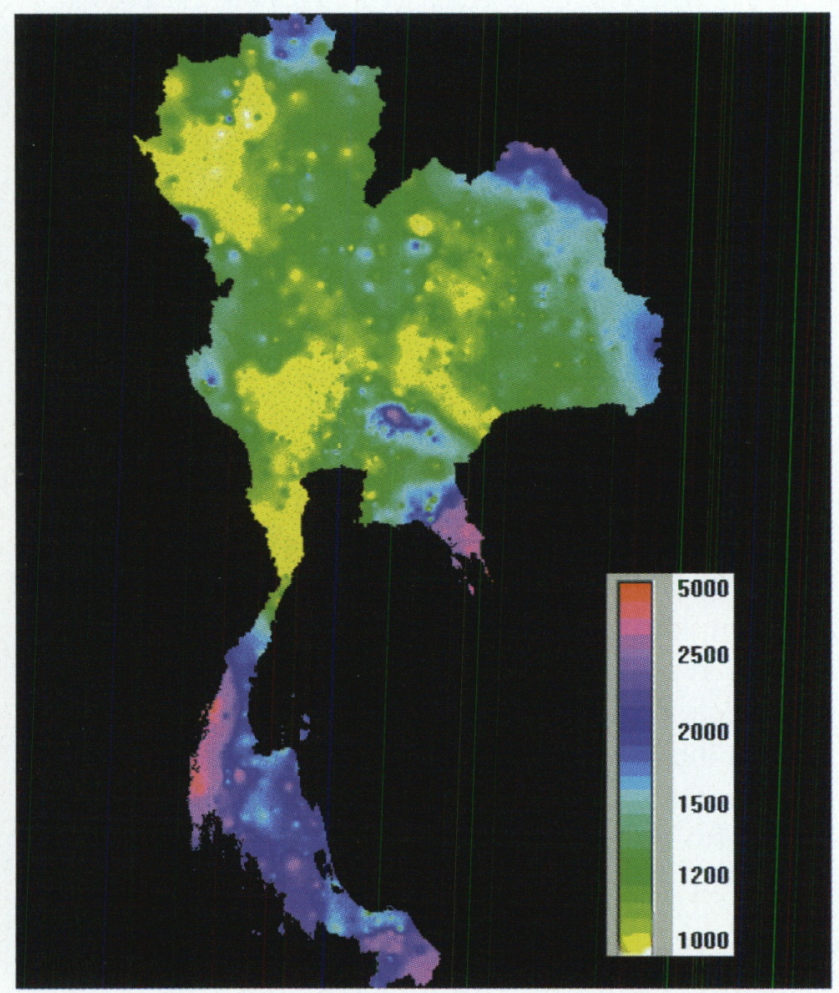

Data from Royal Irrigation Department Thailand, Picture and Created by High Performance Computing Center/NECTEC Thailand.

Fig. 1. - Average yearly rainfall distribution images of Thailand (unit: $\mathrm{mm})$. $(x)$ and the correlation coefficient $(r)$ were calculated. All of the statistical analyses in this study were made using SPSS 7.0 for Windows.

\section{RESULTS}

A ccording to this study, there have been four reports (Nuamtanong et al., 1998; SaksirisamSetasubun et al., 1991) on 33 cross-sectional surveys with geographical data and the prevalence of Gnathostoma spp. L3 that covered 12 provinces in Thailand. The prevalence rates of eel infections in the previous reports of Nuamtanong et al. (1998), Saksirisampant et al. (2002a), Saksirisampant et al. (2002b) and Setasubun et al. (1991) were 0 \%-33.3 \% (11 surveys), $7.0 \%-38.3 \%$ (12 surveys), $10 \%-14 \%$ (three surveys) and $23.1 \%$ $100 \%$ (seven surveys) respectively.

The relation between rainfall (derived from the geographical data) and the prevalence of Gnathostoma spp. L3 in swamp eels (derived from the overall infection rate of Gnathostoma spp. L3) is shown in Figure 2. The least-square equation plot rainfall $(y)$ versus prevalence $(x)$ is $y=9.68 x+1,035.12(r=0.83 ; p<0.01)$. The predicted prevalence of eel infection is shown in Figure 3. Because the season of the survey might be another factor affecting the prevalence of Gnathostoma spp L3 (Saksirisampant et al., 2002), an additional analysis for the effect of this factor was performed. According to the analysis, there is no significant correlation between the prevalence of Gnathostoma spp L3 and the season of the survey $(r=0.09 ; p=0.61)$.

\section{DISCUSSION}

I n 1989, Rojekittikhun et al. (1989) said that the highest intensity of Gnathostoma spp L3 in the swamp -eels could be detected during the rainy season. Saksirisampant et al. (2002) recently mentioned for the possible effect of rainfall on the prevalence of eel infection. The goal of this study was to investigate the relation between rainfall and the prevalence of Gnathostoma spp L3 in swamp eels. The present study retrospectively combined the 33 cross-sectional surveys conducted thus far with the geographical and prevalence data of Gnathostoma spp L3 from 12 provinces in Thailand. The relation between rainfall (derived from the geographical data) and the prevalence of Gnathostoma spp. L3 in swamp eels (derived from the overall infection rate of Gnathostoma spp. L3) was investigated.

According to this study, a significant correlation was discerned between rainfall and the prevalence of eel 


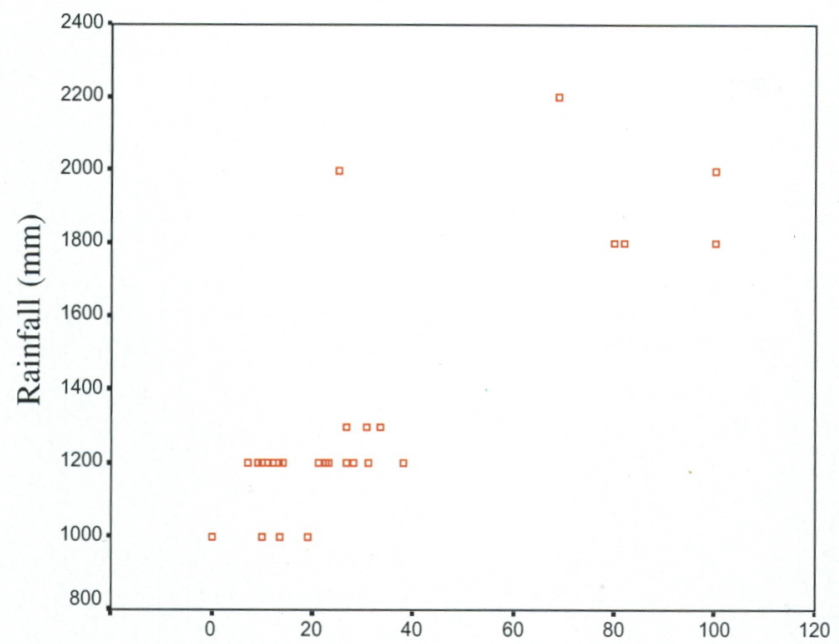

Prevalence of eel infection (\%)

Fig. 2. - Scatterplot between rainfall and the prevalence of Gnathostoma spp. L3 in swamp eels.

infection (Fig. 2). The highest prevalence of eel infection is detected along the Thai-Cambodia border area (Fig. 3). Indeed, Saksirisampant et al. (2002b) mentioned that this area might be the original source of infected eels in Thailand. This study can confirm the effect of rainfall on the prevalence of Gnathostoma spp L3 in the swamp eels (Saksirisampant et al., 2002a). In this study, infection prevalence correlated significantly with rainfall but not with season, which suggests that the prevalence of infection among eels does not depends on season. Indeed, there was a report on the effect of season on the intensity but not for the prevalence of eel infection (Rojekittikhun et al., 1989). Similar to the previous study (Saksirisampant et al., 2002a), the prevalence of eel infection may depend on rainfall rather than season. Therefore, constant surveys of Gnathostoma spp. L3 contamination and control of consumption of swamp eels during the heavy rainfall period are recommended. However, this study focus on only 33 cross- sectional surveys in Thailand; further similar study in other countries to assess the correlation between rainfall and the prevalence of infection is required to substantiate this conclusion.

\section{REFERENCES}

CDC. 1999b "Gnathostomiasis". Available on: http://www. dpd.cdc.gov/DPDx/HTML/gnathostomiasis.htm. Division of Parasitic Diseases, National Center for Infectious Diseases, Centers for Disease Control and Prevention Atlanta, Georgia, 1999.

Daengsvang S. A monograph on the genus Gnathostoma and gnathostomiasis in Thailand. Tokyo : Southeast Asian
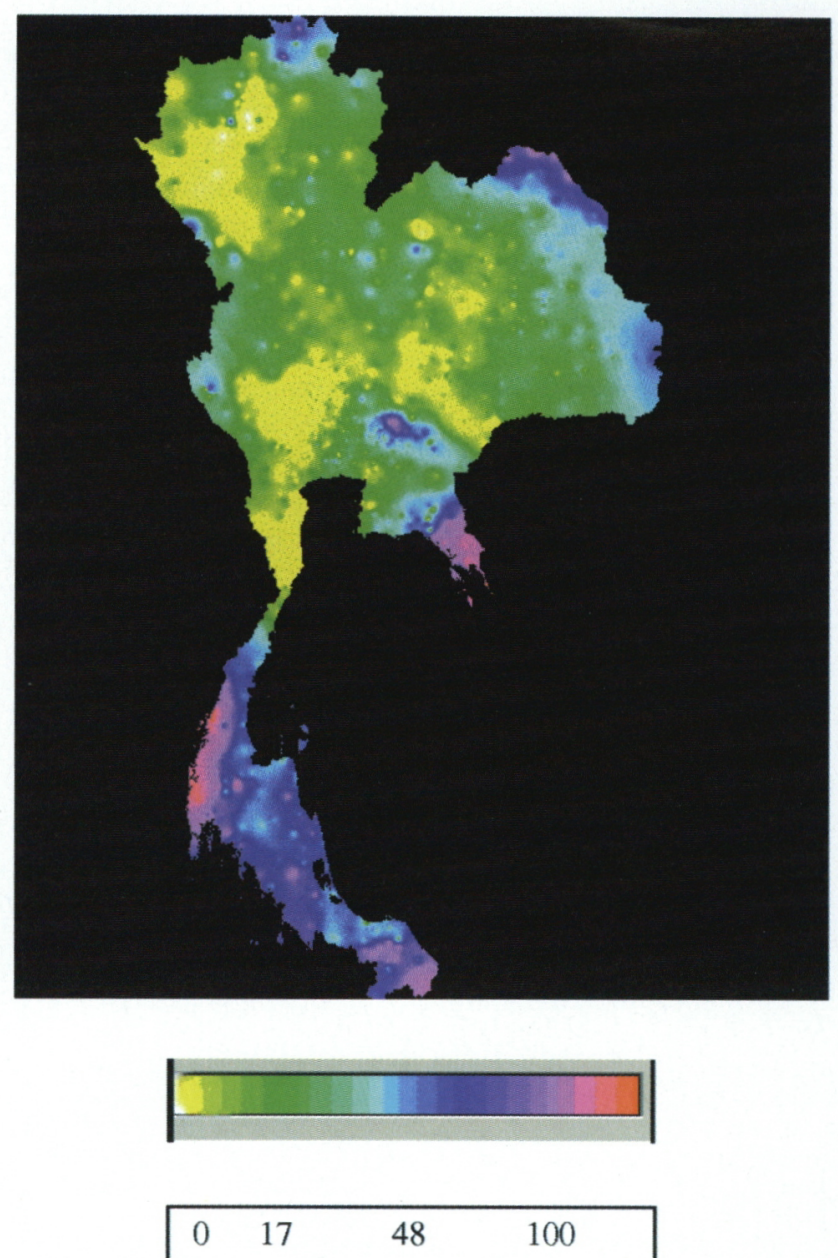

This figure is derived from Figure 1. The least-square equation plot rainfall $(y)$ versus prevalence $(x)$ is $y=9.68 x+1,035.12$.

Fig. 3. - Predicted prevalence of eel infection.

Medical Information Center (SEAMIC), International Medical Foundation of Japan, 1980, p. 85.

DAENGSVANG S. Gnathostoma spinigerum and human gnathostomiasis. A review. In: Sucharit S. (eds). The $25^{\text {th }}$ Anniversary of the Faculty of Tropical Medicine, Mahidol University. Bangkok: Krung Siam Press, 1986, pp. 124-147.

Nuamtanong S., Waikagul J. \& Anantaphruti M.T. Gnathostome infection in swamp eels, Fluta alba, in central Thailand. Southeast Asian Journal of Tropical Med Public Health, 1998, 29, 144-147.

Radomyos P. \& DaEngsvang S. A brief report on Gnathostoma spinigerum specimens obtained from human cases. Southeast Asian Journal of Tropical Med Public Health, 1987, $18,215-217$

Rojekittikhun W., Pubampen S., Hiranyachattada P. et al. A survey on the infective larvae of Gnathostoma spinigerum in fresh water fish sold in the local markets of Bangkok. Journal of Tropical Medicine and Parasitology, 1989, 12, 7-12

SaKsirisampant W., KulKaew K., Nuchprayoon S., Yentakham S. \& WIWANITKIT V. A survey of the infective larvae of Gna- 
thostoma spinigerum in swamp eels bought in a local market in Bangkok, Thailand. Annals of Tropical Medicine and Parasitology, 2002a, 96, 191-195.

SaKsirisampant W., Nuchprayoon S., Wiwanitkit V., Kraivichian K. \& Suwansaksri J. Prevalence and intensity of third stage Gnathostoma spinigerum larvae in swamp eels sold in three large markets in Bangkok, Thailand. Southeast Asian Journal of Tropical Med Public Health, 2002b, 33 (Suppl. 3), 60-62.

Setasuban P., Nuamtanong S., Rojanakittikoon V. et al. Gnathostomiasis in Thailand: a survey on intermediate hosts of Gnathostoma spp. with special reference to a new type of larvae found in Fluta alba. Southeast Asian Journal of Tropical Med Public Health, 1991, 22 (Suppl.), 220-224.

Reçu le 20 janvier 2004 Accepté le 5 juillet 2004 